\title{
Saúde e migrações: a pandemia de Covid-19 e os trabalhadores imigrantes nos frigoríficos do Sul do Brasil
}

\section{Health and migration: the COVID-19 pandemic and immigrant workers in slaughter-houses in southern Brazil}

\author{
Daniel Granada' \\ https://orcid.org/0000-0003-0193-5679 \\ daniel.granada@ufsc.br \\ Marcia Grisotti" \\ https://orcid.org/0000-0003-0389-7100 \\ marcia.grisotti@ufsc.br \\ Priscila Pavan Detoni "II \\ https://orcid.org/0000-0002-7436-2229 \\ ppavandetoni@gmail.com \\ Rosmari Cazarotto IV \\ https://orcid.org/0000-0001-8072-7346 \\ rosmari.cazarotto@univates.br \\ Maria Conceição de Oliveira' \\ https://orcid.org/0000-0002-4731-4993 \\ conceicao.oliveira@ufsc.br \\ I Universidade Federal de Santa Catarina - Curitibanos, SC, Brasil \\ " Universidade Federal de Santa Catarina - Florianópolis, SC, Brasil \\ I"' Universidade Federal da Fronteira Sul - Passo Fundo, RS, Brasil \\ Iv Universidade do Vale do Taquari - Lajeado, RS, Brasil
}




\title{
Resumo
}

Com base na relação saúde e migrações, o artigo analisa as condições sociais e de saúde de imigrantes que trabalham nos frigoríficos de carnes e derivados, nos municípios do interior do Rio Grande do Sul e de Santa Catarina, no contexto da pandemia de Covid-19. As dificuldades de acesso à saúde e aos direitos básicos (como a biossegurança), a discriminação racial, a xenofobia e as vulnerabilidades socioeconômicas são fatores que marcam as condições de trabalho desses migrantes nos frigoríficos do Sul do país. As conclusões apontam a necessidade de implementar políticas públicas de saúde que incorporem novas formas de interdependência entre os sistemas produtivos e os indivíduos e grupos sociais, oriundos de processos migratórios, e a mitigação das vulnerabilidades sociais e iniquidades em saúde às quais esses trabalhadores estão expostos para o enfrentamento à pandemia.

Palavras-chave: migrações e saúde; Covid-19; frigoríficos; pandemia.

\begin{abstract}
Based on approaches to the relationship between health and migration, the article analyzes the social and health conditions of international migrants working in the slaughterhouses for meat and meat products, in the cities of the interior of Rio Grande do Sul and Santa Catarina, in the context of the pandemic de COVID 19. Difficulties in accessing health and basic rights (such as biosafety), racial discrimination, xenophobia and socioeconomic vulnerabilities are factors that mark the working conditions of these migrants in slaughterhouses in the south of the country. The conclusions point to the need to implement public health policies that incorporate new forms of adaptation and integration of individuals and groups, derived from migratory processes, and mitigation of the social vulnerabilities and health iniquities to which these workers are exposed, to face the pandemic.
\end{abstract}

Keywords: health and migrations; COVID-19; slaughterhouses; pandemic. 


\section{Introdução ${ }^{1}$}

A crise sanitária provocada pela disseminação da Covid-19 tem evidenciado uma série de problemas decorrentes do comércio e da circulação rápida de mercadorias, pessoas, animais e microrganismos. Tais problemas impactaram profundamente, embora de forma diferenciada, as esferas globais e regionais de gestão da pandemia, especialmente em relação às diretrizes de governança global em saúde estabelecidas pela Organização Mundial de Saúde (OMS) e a sua efetiva aplicação em todas essas esferas de gestão (Grisotti, 2016, 2020).

A partir do debate sobre saúde e migrações, este artigo analisa as condições sociais e de saúde de imigrantes que trabalham nos frigoríficos de carnes e derivados, nos municípios do interior do Rio Grande do Sul e de Santa Catarina, no contexto da pandemia de Covid-19. Segundo dados publicados na imprensa em maio de 2020, o número desses trabalhadores contaminados representava um terço do total da população que foi diagnosticada com Covid-19 no RS. ${ }^{2}$ As notícias recentes sobre os casos de disseminação do coronavírus em frigoríficos do Sul do país, cuja força de trabalho é em boa parte composta por imigrantes, ${ }^{3}$ levantam questões sobre as ações de informação e de cuidados específicos com a saúde dessa população que, se comparada às populações locais, possui desvantagens cumulativas no acesso aos serviços

1 Este artigo é resultado do projeto da pesquisa "A Covid-19 no Brasil: análise e resposta aos impactos sociais da pandemia entre profissionais de saúde e população em isolamento" A pesquisa responde a uma encomenda do Ministério da Ciência, Tecnologia, Inovações e Comunicações - MCTIC (Convênio Ref.: 0464/20 Finep/UFRGS) que integra a Rede Covid-19 Humanidades. Também resulta de uma pesquisa em curso desde 2018 intitulada "Saúde e migrações no Sul do Brasil de uma perspectiva sócio-antropológica”, contemplado com financiamento do CNPq no edital Universal de 2018 (processo $\mathrm{n}^{\circ}$ 404681/2018-2).

2 O Ministério Público do Trabalho (MPT) contabilizava 2.079 casos confirmados de contaminação pelo novo coronavírus entre trabalhadores de 21 frigoríficos distribuídos por 16 municípios do Rio Grande do Sul (Araujo, 2020).

3 Uma matéria publicada pela BBC News Brasil, baseada em dados recolhidos da Relação Anual de Informações Sociais de 2018, demonstra que o setor de abate e fabricação de produtos de carnes é o que mais emprega imigrantes no país, contabilizando 15.730 estrangeiros trabalhando nesse setor naquele ano (Mota, 2020). 
de saúde ditos universais, conforme já desenvolvido em outros trabalhos. ${ }^{4}$ A pesquisa vem sendo desenvolvida desde 2013 na região do Vale do Taquari, no Rio Grande do Sul, e, a partir de 2018, também no centro-oeste de Santa Catarina, sendo que as peculiaridades do processo migratório para a região do Vale já foram amplamente discutidas e problematizadas pelo grupo de pesquisadores. $^{5}$

Ao longo do artigo é possível compreender que as situações descritas se relacionam com um quadro mais amplo de gestão da pandemia que já foi conceituada como necropolítica (Granada, 2020; Mbembe, 2016). Não há espaço para aprofundar o conceito, mas cabe dizer que concordamos que o Brasil, ao longo de sua história, passou por diversos "regimes necrocropolíticos" - o conceito evoca associações etimologicamente embutidas de gestão, criação de regras e aplicação, invocando não apenas esforços de regulamentação, mas um modo mais organizado de governança e consequentemente controle sobre aqueles que podem viver e os que são deixados morrer. Para nos distanciar das apropriações do senso comum sobre o conceito de "necropolítica", é preciso dizer que compreendemos a pandemia como um fator potencializante de tendências e orientações político-ideológicas que vinham ganhando terreno no país desde pelo menos meados da década passada.

Essas políticas que visam a produção da desigualdade social como um valor positivo foram radicalizadas pelo advento da pandemia, cuja propagação em nosso país foi favorecida por uma gestão intencional voltada para proporcionar a propagação do vírus e consequentemente as mortes por ela decorrentes. ${ }^{6}$ A negação da ciência, o desrespeito às regras internacionalmente recomendadas, a prescrição de medicamentos sem efeitos comprovados são apenas exemplos de um dramático quadro que, para os que vierem depois de nós, demonstrará um dos momentos mais difíceis da história de nosso país. A situação dos trabalhadores imigrantes, colocada em relevo em nosso artigo, oferece mais uma dimensão da tragédia humana pela qual estamos passando.

4 Ver Granada et al. (2017) e Granada e Detoni (2017).

5 Ver Cazarotto e Mejía (2018); Ferreira (2017); Granada e Stork (2018).

6 Para maior detalhe sobre as políticas governamentais que favoreceram a propagação da pandemia no Brasil ver o importante trabalho realizado pela Conectas Direitos Humanos em parceria com o Cepedisa/USP, Boletim direitos na pandemia, em especial o número 10 (Asano et al., 2021). 
Em virtude das restrições de contato vigentes neste período de distanciamento social, ${ }^{7}$ conforme orientado pela OMS, e de haver dados já coletados ao longo da pesquisa, foram utilizadas estratégias de etnografia on-line (Hine, 2015), como conversas via WhatsApp ou Messenger e troca de e-mails, pelas quais coletamos informações junto aos nossos contatos com agentes comunitários de saúde e demais informantes moradores das cidades de Lajeado e Encantado (RS) e Concórdia e Chapecó (SC). Como estratégia de coleta de dados também utilizamos entrevistas disponibilizadas em sites de rádios, além de entrevistas realizadas por telefone com imigrantes haitianos. Outras informações sobre a situação dos frigoríficos foram obtidas através das publicações da imprensa, como notícias em jornais e blogs, e publicações circuladas em redes sociais.

A realização coletiva deste trabalho deixa transparecer diferentes tessituras do texto, em que a própria redação é atravessada por uma construção coletiva em que interagem diferentes mãos para dar forma ao documento compartilhado virtualmente. Esse esforço conjunto pode ser entendido como um artesanato intelectual, conforme a clássica formulação de Mills (1972), no sentido de que comporta dados de densidade variável que exprimem as possibilidades do momento, bem como os interesses e trajetórias de cada um de seus autores. Se na perspectiva clássica a densidade era considerada uma virtude e a superficialidade dos dados deveria ser evitada, na abordagem multissituada a superficialidade ou a densidade dos dados se tornam elementos-chave da análise antropológica (Marcus, 2002).

\section{Migrações e frigoríficos}

A imigração de haitianos se intensificou no Brasil após 2010 em decorrência da situação de crise política e econômica agravada pelo terremoto naquele país, e, no caso do Vale do Taquari, é basicamente caracterizada por ser uma migração

7 O chamado "distanciamento social" tem sido definido como o conjunto de medidas que se destinam a reduzir as interações entre os indivíduos de uma dada comunidade, incluindo pessoas já infectadas ou não, e, neste caso, ainda não isoladas. Essas medidas incluem o fechamento de escolas, locais de trabalho, comércio, eventos, redução e restrição da mobilidade inter e intramunicipal, entre outros (Aquino et al., 2020). 
de trabalho (Granada; Stork, 2018). No caso de Santa Catarina, também se trata de uma imigração laboral, inicialmente haitiana e nos últimos anos venezuelana, e existem relatos de imigrantes sobre exploração de mão de obra, preconceito, dificuldades de moradia e de acesso aos serviços de saúde. Nesse estado, o foco do estudo concentra-se em Chapecó e Concórdia, cidades que abrigam grande número de imigrantes que trabalham nas indústrias de alimentos.

As indústrias frigoríficas têm sido foco de infecção e disseminação da Covid-19 também em outros países, como Estados Unidos, Alemanha e França (Mota, 2020). As condições no ambiente de trabalho e os termos de ajustamentos de conduta gerados pelas procuradorias do Trabalho após os primeiros surtos da infecção nesses ambientes contribuíram para o elevado número de casos confirmados.

Os casos registrados nos frigoríficos do Sul do Brasil (Chapecó, Concórdia, Lajeado e Encantado) colocam em evidência o descompasso, a ser investigado, entre os altos índices de qualidade de vida preconizados oficialmente para esses municípios e a contabilização de altos índices de casos confirmados de Covid-19 em ambientes marcados pela acentuada presença de trabalhadores imigrantes. ${ }^{8}$

\section{Corpos, carnes e ossos}

No comunicado à imprensa intitulado "Os abatedouros: um alvo maior para a prevenção da Covid-19”, publicado em 24 de junho de 2020, a Academia Nacional de Medicina e a Academia Veterinária da França lançam um alerta sobre a situação dos frigoríficos (Les abattoirs..., 2020). O conteúdo do documento explica que desde o início da pandemia os abatedouros industriais (especialmente de porcos e aves) foram locais importantes de disseminação da Covid-19 em diversos países, entre eles França, Alemanha, Holanda, Irlanda, Austrália, Reino Unido, Estados Unidos, Canadá e Brasil. No maior abatedouro de porcos

8 O IDH (Índice de Desenvolvimento Humano), indicador composto por renda, saúde e educação, segundo dados disponíveis do IBGE que datam de 2010, colocam Lajeado em $16^{\circ}$ lugar no estado do Rio Grande do Sul $(0,778)$ e Encantado em $36^{\circ}$ lugar $(0,767)$. Em Santa Catarina, a cidade de Chapecó figura na posição $18(0,790)$, enquanto Concórdia na posição $11(0,800)$ (Instituto Brasileiro de Geografia e Estatística, 2020). 
da Europa, na Alemanha, de 6.139 pessoas que trabalhavam no estabelecimento 1.500 foram afetadas, na maioria dos casos devido à situação de vulnerabilidade e precariedade social na qual se encontravam (Les abattoirs..., 2020).

Segundo esse comunicado, a origem da contaminação é humana e não tem relação com os animais abatidos. Foi experimentalmente demonstrado que os porcos e as aves eram resistentes ao Sars-CoV-2 e que não haveria perigo de contaminação para os consumidores. A possibilidade da contaminação em animais (e sua transmissão para os humanos) é tema de grande impacto social em alguns países europeus, pois traz à memória as experiências de abate de animais, como foi o caso da bovine spongiform encephalopathy (conhecida popularmente como mal da vaca louca). Também é mencionado que os fatores ambientais - a atmosfera dos locais de abate e corte é fria e úmida - favoreceram o desenvolvimento de focos de Covid-19 nos abatedouros. Nos ateliês de desossa e corte, onde frequentemente as temperaturas são baixas, o vapor d'água liberado pela respiração dos trabalhadores leva a uma condensação rápida e a uma umidificação das máscaras, o que prejudicaria sua capacidade de filtração. Em suma, as condições de trabalho tornam difícil o respeito a um distanciamento físico, tanto nos vestiários como na linha de produção (Les abattoirs..., 2020).

Ainda de acordo com o comunicado, os fatores socioeconômicos desempenham um papel importante no risco de Covid-19. A diversidade de línguas e de culturas dos trabalhadores estrangeiros seria um fator que complicaria a aplicação e a operacionalização de medidas de biossegurança. Os trabalhadores estrangeiros são contratados, frequentemente, através de empresas terceirizadas, e são pessoas que vivem de modo precário, em alojamentos coletivos com forte densidade humana e em habitações insalubres com famílias numerosas, onde, em virtude das condições de vida, aumentam os riscos de contágio. Somam-se a isso os meios de deslocamento desses trabalhadores em transporte coletivo, o que favorece a difusão do vírus, tanto no interior quanto no exterior desses estabelecimentos (Les abattoirs..., 2020).

Diante desses argumentos recomendam: integrar, entre as pessoas em situação de precariedade, os trabalhadores dos abatedouros em um programa nacional de testagem da Covid-19; reforçar a fiscalização médica sobre os trabalhadores dos abatedouros; reforçar o controle das condições de trabalho e o respeito das medidas de prevenção, segundo instrução conjunta do Ministério do 
Trabalho e do Ministério da Agricultura e da Alimentação daquele país. Esses controles devem visar, prioritariamente, os equipamentos de proteção individual, os meios de distanciamento físico e as condições de alojamento coletivo. Embora não seja possível averiguar a efetividade prática das recomendações sociotécnicas preconizadas pelo documento, a sua produção e divulgação sinalizam possíveis tomadas de decisões e atribuição de responsabilidades, o que não acontece no caso brasileiro, onde, apesar das reiteradas denúncias de contaminação entre trabalhadores dos frigoríficos, não encontramos protocolos similares.

No caso brasileiro, os locais de abate, corte e desossa de animais se encontram em condições de trabalho precárias, às quais se submetem trabalhadores que não têm outra alternativa além de aceitar condições desumanas de emprego e de salário que permitam sua sobrevivência.

Como explica Antunes (2020), a pandemia de coronavírus pode ser compreendida como consequência de uma simbiose entre uma crise estrutural do capital e crises sociais e políticas profundas. A imbricação trágica entre o sistema de metabolismo antissocial do capital, a crise estrutural e a explosão do coronavírus pode ser sintetizada na expressão "capitalismo pandêmico" (Antunes, 2020, p. 17).

Considerando todas essas adversidades, às quais se soma a pandemia, busca-se entender os frigoríficos como meio de subsistência de muitos migrantes, ao mesmo tempo que se configuram como focos de contágio de Covid-19.

\section{Trabalhadores imigrantes e a interiorização da Covid-19 no Rio Grande do Sul: o caso das cidades de Lajeado e Encantado}

O primeiro caso de infecção pelo novo coronavírus no estado do Rio Grande do Sul, confirmado no dia 10/03/2020, foi de um homem de Campo Bom que retornou de viagem à Itália (Secretaria da Saúde, 2020). No Vale do Taquari, região formada por 36 municípios e localizada na porção centro-oriental do Rio Grande do Sul, os primeiros casos confirmados foram no dia 21 de março, nos municípios de Lajeado e Estrela, tratando-se de pessoas que retornaram de viagens à Europa e de um cruzeiro marítimo pela costa brasileira (Ribeiro, N., 2020). No dia 10/06/2020, o Rio Grande do Sul já havia chegado 
a 13.619 casos confirmados, sendo 1.489 em Lajeado. Encantado teve o primeiro caso confirmado em 07/04/2020 (Hautrive; Cássia, 2020) e o primeiro óbito em 16/05/2020, sendo de um haitiano que se encontrava em tratamento devido a um câncer e que havia trabalhado em um frigorífico até o final de 2018 (Pedersini, 2020).

Conforme a Relação Anual de Informações Sociais, disponibilizada pelo Ministério da Economia (Brasil, 2019), em 2018 o contingente de imigrantes internacionais com vínculos formais de trabalho no Vale do Taquari era de 1.310 pessoas, o que representava $8,47 \%$ do total da mão de obra estrangeira contratada formalmente no estado do Rio Grande do Sul. Na referida região, $82 \%$ dos trabalhadores formais estrangeiros atuavam no setor da indústria de transformação, seguidos de $8 \%$ em serviços, $6 \%$ no comércio e $3 \%$ na construção civil. A principal nacionalidade estrangeira no mercado de trabalho formal era a haitiana, perfazendo $80,4 \%$ do total, seguida da nacionalidade argentina, com $4,6 \%$. Quanto à faixa etária, $42 \%$ dos imigrantes com vínculo formal de trabalho tinham de 30 a 39 anos. Porém, ao totalizar o intervalo de idades entre 18 e 49 anos, este alcança 94\% das pessoas (Cazarotto; Sindelar, 2020). ${ }^{9}$

As cidades de Lajeado e Encantado desempenham importante papel nos complexos agroindustriais de carne de frango e de suíno instalados na região. São 12 unidades de beneficiamento de produtos cárneos distribuídas pelos municípios da região. A cidade de Lajeado conta com dois frigoríficos, Minuano e BRF (Brasil Foods), e possui o maior número de vínculos formais de trabalho do estado do Rio Grande do Sul: mais de 4.982 trabalhadores nesse setor (Brasil, 2019). A cidade de Encantado, com o frigorífico Dália Alimentos, contribui para que o município seja o segundo maior empregador do Rio Grande do Sul nessa área, com 1.690 empregos. Devido à concentração expressiva de postos de trabalho e à proximidade com as cidades de seus entornos, muitos trabalhadores deslocam-se diariamente de cidades vizinhas, o que contribui para a disseminação do vírus.

Os imigrantes internacionais contemporâneos também se inserem nessa dinâmica. Conforme relata Chaparini (2020): "O foco é nos trabalhadores

9 O protagonismo dessas cidades como polos de concentração de imigrantes laborais já foi bastante discutido pelos autores em outros trabalho. Cf. Cazarotto e Mejía (2018) e Granada e Stork (2018). 
dos frigoríficos [de Lajeado]. De acordo com o secretário [de Saúde] Elmar Schneider, 169 moradores de Estrela trabalham nas unidades. Destes, 79 são haitianos." Essa situação de contaminação e de propagação do vírus entre as pessoas de convívio, como familiares e outras pessoas das cidades próximas, começou a preocupar a região. No dia 19 de maio, a cidade de Estrela informou que recebeu os resultados dos testes feitos nos trabalhadores da BRF que residem no município e 30 deram positivo (Estrela..., 2020).

Faz-se necessário indagar se estes trabalhadores infectados e os que estão ainda atuando em frigoríficos possuem os equipamentos de proteção individual (EPI), como máscaras, aventais, luvas, gorros e macacões descartáveis, uma vez que não há nem materiais para os profissionais de saúde que estão atuando na linha de frente de enfrentamento ao vírus (Oliveira et al., 2020). A falta de protocolos de biossegurança aliada às incertezas quanto à epidemiologia, diagnóstico, tratamento e prevenção da Covid-19, aumentam a insegurança em relação ao contato com indivíduos infectados.

Os imigrantes já estavam em condições precárias de trabalho e moradia, uma vez que não possuem fiadores locais para alugar melhores residências, o que lhes obriga a dividir uma casa entre várias famílias e estar em lugares insalubres, muitas vezes invadidos pelas enchentes (Granada et al., 2017). Esse fato se repetiu fortemente com a enchente de julho de 2020, que atingiu tanto imigrantes de Lajeado como de Encantado que residem em áreas próximas aos locais de trabalho, porém desvalorizadas pelo setor imobiliário devido às cheias. Considerando o número de pessoas em uma residência e o acesso aos insumos de proteção e higiene, essas pessoas podem acabar por se tornar os bodes expiatórios da disseminação do vírus.

As características dos locais de moradia favorecem que, num contexto de pandemia em que se estimula o distanciamento social, haja aglomerações não apenas nas residências onde frequentemente habitam diversas pessoas, mas também, no caso de catástrofes ambientais como as enchentes sazonais na região, nos ginásios municipais para onde as famílias que moram em áreas inundáveis são removidas. Nesses locais, o distanciamento social é praticamente impossível, agravando o quadro de exposição ao contágio. As precárias condições de moradia dessa população colocam limites para a política de prevenção materializada na política do fique em casa. Afinal, quem pode ficar em casa e como manter distância física? 
Após o pedido da Justiça estadual de 15 dias de interdição dos frigoríficos de Lajeado, Minuano (em 07/05/2020) e BRF (em 08/05/2020), as aglomerações nas ruas se intensificaram. O objetivo do fechamento temporário foi o de evitar a propagação dos contágios do novo coronavírus em função do alto índice de funcionários que testaram positivo nestes estabelecimentos (Hautrive, 2020). O fato das aglomerações como reflexo do fechamento dos frigoríficos foi relatado pelo jornal Independente: os moradores reclamaram da movimentação de pessoas em bares na área central de Lajeado (Maior..., 2020).

\section{Trabalhadores imigrantes e a interiorização da Covid 19 em Santa Catarina: os casos em Chapecó e Concórdia}

O caso das migrações no estado de Santa Catarina apresentou duas fases do processo migratório. De acordo com Magalhães (2017), a primeira fase estaria relacionada com o recrutamento, por empresas do estado, diretamente da região Norte e de São Paulo, em um contexto de maior mobilidade Norte-Sul da população de imigrantes..$^{10}$ Para o autor, a segunda fase inicia em 2014, e é caracterizada por processos de mobilidade interna do Vale do Itajaí para as regiões do centro-oeste catarinense, em particular aquelas localidades que possuem atividades econômicas com grande demanda de mão de obra e alta volatilidade de trabalhadores, no caso dos frigoríficos.

No oeste de Santa Catarina, o movimento migratório tem características semelhantes. O fluxo iniciado em 2011 na região de Chapecó contabilizava, em 2016, em torno de 4.000 imigrantes internacionais que haviam procurado a divisão regional da Polícia Federal para providências com relação a passaporte, dos quais $90 \%$ eram haitianos, e os demais senegaleses e de outras nacionalidades (Bordignon; Langoski, 2018). Os dados referem-se à região de abrangência da delegacia que responde por 84 municípios, sendo que, segundo as autoras, a maior parte dos imigrantes encontram-se instalados em Chapecó.

10 Magalhães (2017) cita o papel de destaque de três empresas catarinenses no recrutamento de haitianos: a Multilog, a Ambiental e a Imbrasul Construtora e Incorporadora, as quais atuam no setor de logística, limpeza urbana e construção civil, respectivamente. 
Em Concórdia o processo é semelhante: os trabalhos existentes sobre o tema expõem dinâmicas migratórias associadas à migração de trabalho e relacionadas com a grande demanda de trabalhadores nos frigoríficos, onde se estima a presença de aproximadamente 500 trabalhadores migrantes na BRF de Concórdia (Ribeiro, V., 2018). Tanto nos estudos sobre as migrações no centro-oeste catarinense quanto na região do Vale do Taquari destacam-se o papel das redes sociais nos processos migratórios, os processos discriminatórios em função da cor da pele e da nacionalidade estrangeira, as dificuldades com as locações para moradia, a vontade dos imigrantes de conquistar postos de trabalho mais valorizados, bem como os casos de exploração de sua mão de obra ver Cazarotto e Mejía (2018); Ferreira, 2017; Granada e Stork (2018); Sales (2016); Magalhães e Baeninger (2017); Magalhães (2017); Bordignon e Langoski (2018); Risson, Magro e Lajús (2017); Ribeiro, V. (2018). O estado teve seu primeiro caso confirmado no dia 13/03/2020. No dia 17 do mesmo mês, com sete casos contabilizados, o governador de Santa Catarina publicou um decreto contendo medidas de restrição de mobilidade e distanciamento social (Santa Catarina, 2020). Essa medida é considerada fundamental na contenção da expansão da contaminação no estado, onde até março foram contabilizados 235 oficialmente infectados. Será a partir da flexibilização, decisão tomada a partir de 01/04/2020, que o número de casos começará a subir. Assim, em 14/04/2020, o estado já contabilizava 853 casos confirmados e 31 óbitos. Inicialmente, a disseminação do coronavírus se concentrou na faixa litorânea, na Grande Florianópolis, no Vale do Itajaí e em alguns municípios do sul catarinense.

Até abril foram contabilizados apenas 20 casos confirmados na mesorregião Oeste e a imprensa começava a noticiar os dois primeiros casos confirmados de Covid-19 em Ipumirim, município com pouco mais de 7.000 habitantes, vizinho a Concórdia. Os trabalhadores são funcionários da JBS, que, em reportagem ao G1 SC, afirmou estar prestando atendimento às famílias e tomando as medidas de segurança e prevenção preconizadas pela OMS (Agroindústria..., 2020). Um mês depois, em 15/05/2020, os jornais noticiavam que Chapecó, com 446 casos confirmados, era o segundo município com maior número de casos, atrás apenas de Florianópolis, com 466. O município de Concórdia se encontrava até então na sexta posição em número de casos, com 241 confirmados (SC tem..., 2020). No final de junho, o mesmo jornal trazia como manchete que Santa Catarina passava de 9.600 casos de coronavírus com 148 mortes, 
com o subtítulo: "Chapecó voltou a ser a cidade com mais pacientes, com 939. Concórdia aparece logo em seguida, com 935” (Caldas, 2020).

Em entrevista realizada com um trabalhador informante de um frigorífico em Chapecó, que conta com cerca de 6.000 trabalhadores, dos quais 1.200 são imigrantes haitianos e senegaleses e em torno de 600 são venezuelanos contratados no ano passado (2019), ele relatou que:

As medidas tomadas para a higienização e distanciamento seguro entre os trabalhadores não são suficientes, afinal os trabalhadores vêm todos no mesmo ônibus dos municípios ao redor com lotação máxima, e não houve revezamento no transporte, nem na produção e pouco nas áreas administrativas. Como manter um distanciamento com 6.000 pessoas trabalhando em um mesmo lugar? Tudo isso causa grande sofrimento para todos trabalhadores, ao retornarem para suas casas e encontrarem seus filhos, com medo da transmissão do vírus. Ainda mais para aqueles que estão em situação precária de moradia, por estarem há pouco tempo na região, e parte da família ainda estar na condição de refugiado, sem documentação e por isso acabam nem acessando os serviços de saúde. (Entrevista com trabalhador de frigorífico por WhatsApp em 12/08/2020).

Segundo os dados do relatório do Observatório das Migrações, entre janeiro e julho de 2019 foram contratados 8.382 trabalhadores migrantes com carteira assinada no estado de Santa Catarina (Cavalcanti; Oliveira; Macedo, 2019). Em matéria publicada em 16/07/2020, o maior jornal do estado noticiava que Santa Catarina tinha 3.132 trabalhadores do setor frigorífico infectados e 2.399 casos suspeitos. A mesma notícia informou que o Ministério Público do Trabalho exigiu a retirada da premiação por assiduidade em dinheiro para evitar que os funcionários escondessem os sintomas da doença (Bastos, A., 2020).

\section{Corpos, carnes e a pandemia}

Se analisarmos o caso da disseminação da Covid-19 nos frigoríficos nas cidades de Lajeado e Encantado, e de Chapecó e Concórdia, podemos encontrar diversos pontos em comum que auxiliam na interpretação das relações entre mobilidade humana, disseminação do vírus e processos de saúde e adoecimento. 
A tentativa de compreender os motivos pelos quais essas cidades (que concentram frigoríficos, possuem altos índices de qualidade de vida e atraem imigrantes) apresentaram os maiores números de casos confirmados de Covid-19, no interior de seus respectivos estados, nos provoca a pensar sobre a interiorização e o impacto da pandemia em cidades de médio e pequeno porte do interior do país. Além das condições de trabalho, sugere-se a hipótese de que os frigoríficos, classificados como serviços essenciais, são também, polos de circulação de pessoas e mercadorias que não pararam durante a orientação do isolamento. O transporte dos produtos faz com que exista circulação por via rodoviária entre as cidades do interior e as capitais. Nesse sentido, a exploração da mão de obra presente nos frigoríficos, na ocasião da pandemia, se potencializa, evidenciando as vulnerabilidades e fragilidades relacionadas a esses trabalhadores migrantes. A disseminação do vírus Sars-CoV-2 nas cidades foco deste estudo desvenda uma relação subterrânea, que se torna evidente com o impacto da doença, entre a exploração do trabalho e a consequente baixa remuneração juntamente com a dependência destes trabalhadores ao emprego, mesmo nas condições descritas no artigo.

A classificação dos frigoríficos como serviços essenciais, por se tratar de indústria alimentícia, fez com que as rotinas dos trabalhadores não fossem alteradas pelos decretos de distanciamento social (Brasil, 2020). Nesse caso, transparece uma complexa relação entre mobilidade humana, capitalismo e pandemia. Longe de serem fortuitas, essas relações são previsíveis, e se inserem em um quadro mais amplo de políticas que se destinam a atribuir o poder de escolher quais indivíduos devem ser protegidos e quais podem ser expostos aos riscos de contaminação.

A falta de medidas de contenção da disseminação do vírus nos frigoríficos em nome da produtividade teve como efeito colateral inicial a suspensão das importações pela China. No final de junho, diversos jornais noticiavam que a China havia suspendido a importação de carnes de determinados frigoríficos (China..., 2020). E surge a notícia de que foram identificados traços de Sars-CoV-2 em embalagens de frango exportado do Brasil, e, segundo a reportagem, a empresa responsável pelo envio das asas de frango contaminadas para o país era de Santa Catarina (Mendonça, 2020).

A realidade trágica da pandemia, quando passamos a marca de 200.000 mortos nos registros oficiais do governo brasileiro, acaba por descortinar com 
maior evidência um presente sombrio para os migrantes laborais, pois, além de todos os riscos das travessias para chegar ao Brasil citados por Cristiana Bastos (2020), são postos a trabalhar em condições de salubridade questionáveis, expondo sua saúde a riscos de contaminação."

No caso dos frigoríficos, aquelas pessoas que abatem e cortam os animais também são classificadas como menos prioritárias. É um setor em que a produção é essencial, mas as pessoas são descartáveis. O controle dos corpos, nesse caso, passa por aqueles cujos corpos não podem parar de produzir, e, se pararem por força da doença, poderão ser substituídos a baixo custo. A necropolítica (Mbembe, 2016) aqui age de forma dissimulada, em um quadro em que a manutenção das atividades essenciais para a vida de certas pessoas pode colocar em risco a vida dos que podem ser deixados para adoecer ou morrer.

Constitui-se, assim, nos frigoríficos da região Sul do Brasil um triste cenário. No local onde se abatem e cortam os animais não humanos longe dos olhos dos consumidores, existem também outras taxonomias para os animais humanos, que os dividem em diferentes categorias de humanidade.

\section{Referências}

LES ABATTOIRS: une cible majeure pour la prévention de la COVID-19. Bulletin de l'Académie Nationale de Médecine, Issy-les-Moulineaux, v. 204, n. 8, p. 788-789, 2020. DOI: https://doi.org/10.1016/j.banm.2020.07.027.

AGROINDÚSTRIA do Oeste de SC tem dois funcionários internados com novo coronavírus. G1 SC, Florianópolis, 14 abr. 2020. Disponível em: https://g1.globo.com/sc/ santa-catarina/noticia/2020/04/14/agroindustria-do-oeste-de-sc-tem-dois-funcionarios-internados-com-novo-coronavirus.ghtml. Acesso em: 21 ago. 2020.

ANTUNES, R. Coronavírus: o trabalho sob fogo cruzado. São Paulo: Boitempo, 2020.

11 É importante mencionar que quando submetemos o artigo para avaliação em agosto de 2020 estávamos passando a marca de 100.000 mortos na pandemia. Agradecemos o comentário do parecerista que solicitou para situarmos ou atualizarmos o número, pois no momento em que estamos fazendo as correções, em fevereiro de 2021, estamos ultrapassando a marca de 230.000 mortos; provavelmente, quando o artigo for publicado, já estaremos com outro número que traduzirá a evolução da pandemia. 
AQUINO, E. M. L. et al. Medidas de distanciamento social no controle da pandemia de COVID-19: potenciais impactos e desafios no Brasil. Ciência \& Saúde Coletiva, Rio de Janeiro, v. 25, supl. 1, p. 2423-2446, jun. 2020. Disponível em: http://www.scielo. br/scielo.php?script=sci_arttext\&pid=S1413-81232020006702423\&lng=en\&nrm=iso. Acesso em: 13 ago. 2020.

ARAUJO, L. A. Coronavírus: frigoríficos concentram um terço dos casos de covid-19 no RS, diz Ministério Público do Trabalho. UOL, São Paulo, 26 maio 2020. Disponível em: https://noticias.uol.com.br/saude/ultimas-noticias/bbc/2020/05/26/coronavirus-frigorificos-concentram-um-terco-dos-casos-de-covid-19-no-rs-diz-mp-do-trabalho.htm?cmpid=copiaecola. Acesso em: 18 ago. 2020.

ASANO, C. L. et al. (ed.). Direitos na pandemia: monitoramento e análise das normas jurídicas de resposta à Covid-19 no Brasil. São Paulo: Conectas Direitos Humanos: Centro de Pesquisas e Estudos sobre Direito Sanitário, n. 10, 20 jan. 2021. Disponível em: https://www.conectas.org/publicacoes/download/boletim-direitos-na-pandemia-no-10. Acesso em: 5 fev. 2021.

BASTOS, A. Coronavírus em frigoríficos: SC tem 3,1 mil trabalhadores do setor infectados e 2,4 mil casos suspeitos. Diário Catarinense, Florianópolis, 16 jul. 2020. Disponível em: https://www.nsctotal.com.br/noticias/casos-de-coronavirus-em-frigorificos-de-santa-catarina. Acesso em: 22 ago. 2020.

BASTOS, C. Febre a bordo: migrantes, epidemias, quarentenas. Horizontes Antropológicos, Porto Alegre, ano 26, n. 57, p. 27-55, ago. 2020.

BORDIGNON, S. A. F.; LANGOSKI, D. T. GEIROSC - Grupo de estudo sobre imigrações para a região oeste de Santa Catarina: apoio e atendimento ao imigrante. Brazilian Journal of Development, Curitiba, v. 4, n. 3, p. 750-765, jun. 2018.

BRASIL. Ministério da Economia. Relação Anual de Informações Sociais - RAIS. Brasília: Ministério da Economia, 2019. Disponível em: http://bi.mte.gov.br/bgcaged/ login.php. Acesso em: 20 ago. 2020.

BRASIL. Decreto $n^{\circ} 10.282$, de 20 de março de 2020. Regulamenta a Lei $n^{\circ} 13.979$, de 6 de fevereiro de 2020, para definir os serviços públicos e as atividades essenciais. Brasília: Presidência da República, Secretaria-Geral, Subchefia para Assuntos Jurídicos, 2020. Disponível em: http://www.planalto.gov.br/ccivil_03/_ato2019-2022/2020/ decreto/D10282.htm. Acesso em: 21 ago. 2020.

CALDAS, J. Santa Catarina passa de 9,6 mil casos de coronavírus, com 148 mortes. G1 SC, Florianópolis, 2 jun. 2020. Disponível em: https://g1.globo.com/sc/santa-catarina/noticia/2020/06/02/santa-catarina-passa-de-96-mil-casos-de-coronavirus-com-148-mortes.ghtml. Acesso em: 21 ago. 2020. 
CAVALCANTI, L.; OLIVEIRA, T.; MACEDO, M. (org.). Imigração e refúgio no Brasil: relatório anual 2019. Brasília: OBMigra, 2019. Disponível em: https://portaldeimigracao. mj.gov.br/images/relatorio-anual/RELAT\%C3\%93RIO\%20ANUAL\%20OBMigra\%20 2019.pdf. Acesso em: 22 ago. 2020.

CAZAROTTO, R. T.; MEJÍA, M. R. G. Repercussão socioespacial da imigração haitiana numa pequena cidade: o caso de Encantado - Rio Grande do Sul - Brasil. Ra'eGa, Curitiba, v. 45, p. 170-186, dez. 2018.

CAZAROTTO, R. T.; SINDELAR, F. C. W. A dinâmica da imigração laboral internacional contemporânea: o caso do Vale do Taquari/RS no período de 2010-2018. Geosul, Florianópolis, v. 35, n. 75, 2020. Disponível em: https://periodicos.ufsc.br/index.php/ geosul/article/view/1982-5153.2020v35n75p257/43425. Acesso em: 19 ago. 2020.

CHAPARINI, M. Município orienta haitianos. A Hora, Lajeado, 30 abr. 2020. Disponível em: https://grupoahora.net.br/conteudos/2020/04/30/municipio-orienta-haitianos/. Acesso em: 20 jun. 2020.

CHINA suspende importações de frigoríficos brasileiros, diz ministério. Folha de $S$. Paulo, São Paulo, 30 jun. 2020. Disponível em: https://wwwl.folha.uol.com.br/mercado/2020/06/china-suspende-importacoes-de-frigorificos-brasileiros-diz-ministerio.shtml. Acesso em: 22 ago. 2020.

ESTRELA recebe resultado de testes da Covid 19 em funcionários da BRF. Grupo Independente, Lajeado, 19 maio 2020. Disponível em: https://independente.com.br/ estrela-recebe-resultado-de-testes-da-covid-19-em-funcionarios-da-brf/. Acesso em: 20 jun. 2020.

FERREIRA, D. G. Negritude e diferença no caso da imigração haitiana no sul do Brasil. Périplos: Revista de Estudos Sobre Migrações, Brasília, v. 1, n. 1, p. 118-125, 2017. Disponível em: https://periodicos.unb.br/index.php/obmigra_periplos/article/ view/6556. Acesso em: 25 ago. 2020.

GRANADA, D. A gestão da pandemia do coronavírus (Covid 19) no Brasil e a necropolítica: um ensaio sobre uma tragédia anunciada. In: GROSSI, M. P.; TONIOL, R. (org.). Cientistas sociais e o coronavírus. São Paulo: Anpocs; Florianópolis: Tribo da Ilha, 2020. p. 541-543.

GRANADA, D.; DETONI, P. Corpos fora do lugar: saúde e migração no caso de haitianos no Sul do Brasil. Temáticas, Campinas, v. 25, n. 49/50, p. 115-138, 2017.

GRANADA, D.; STORCK, F. P. Migrações contemporâneas: relações de trabalho e direitos humanos no caso dos haitianos no sul do Brasil. In: MEJÍA, M. G. (org.). Migrações e direitos humanos: problemática socioambiental. Lajeado: Ed. da Univates, 2018. p. 149-156. 
GRANADA, D. et al. Discutir saúde e imigração no contexto atual de intensa mobilidade humana. Interface (Botucatu), Botucatu, v. 21, n. 61, p. 285-296, jun. 2017. Disponível em: http://www.scielo.br/scielo.php?script=sci_arttext\&pid=S1414$-32832017000200285 \& \operatorname{lng}=$ en\&nrm=iso. Acesso em: 8 jun. 2020.

GRISOTTI, M. Governança em saúde global no contexto das doenças infecciosas emergentes. Civitas, Porto Alegre, v. 16, n. 3, p. 377-398, set. 2016. Disponível em: http:// www.scielo.br/scielo.php?script=sci_arttext\&pid=S1519-60892016000300003\&lng= en\&nrm=iso. Acesso em: 18 ago. 2020.

GRISOTTI, M. Pandemia de Covid-19: agenda de pesquisas em contextos de incertezas e contribuições das ciências sociais. Physis, Rio de Janeiro, v. 30, n. 2, e300202, 2020. Disponível em: http://www.scielo.br/scielo.php?script=sci arttext\&pid=S0103-73312020000200301\&lng=en\&nrm=iso. Acesso em: 18 ago. 2020.

HAUTRIVE, G. BRF retoma produção com mais de 50\% dos funcionários. Grupo Independente, Lajeado, 27 maio 2020. Disponível em: https://independente.com.br/brf-retoma-producao-com-mais-de-50-dos-funcionarios/. Acesso em: 23 jul. 2020.

HAUTRIVE, G.; CÁSSIA, R. de. Encantado confirma primeiro caso de coronavírus no município; no Vale são 21. Grupo Independente, Lajeado, 7 abr. 2020. Disponível em: https://independente.com.br/encantado-confirma-primeiro-caso-de-coronavirus-no-municipio-no-vale-sao-21/. Acesso em: 29 jul. 2020.

HINE, C. Ethnography for the internet: embedded, embodied and everyday. London: Bloomsbury, 2015.

INSTITUTO BRASILEIRO DE GEOGRAFIA E ESTATÍSTICA. Cidades. Brasília: IBGE, 2020. Disponível em: https://cidades.ibge.gov.br/. Acesso em: 19 ago. 2020.

MAGALHÃES, L. F. A. A imigração haitiana em Santa Catarina: perfil sociodemográfico do fluxo, contradições da inserção laboral e dependência de remessas no Haiti. 2017. Tese (Doutorado em Demografia) - Instituto de Filosofia e Ciências Humanas, Universidade Estadual de Campinas, Campinas, 2017. Disponível em: http://repositorio. unicamp.br/jspui/handle/REPOSIP/322136. Acesso em: 2 jun. 2020.

MAGALHÃES, L. F.; BAENINGER, R. Imigração haitiana no estado de Santa Catarina: fases do fluxo e contradições da inserção laboral. Geografias, Belo Horizonte, ed. esp., p. 100-111, 2017.

MAIOR movimento nas ruas tem sido de estrangeiros em Lajeado, afirma proprietário de bar. Grupo Independente, Lajeado, 13 maio 2020. Disponível em: https:// independente.com.br/maior-movimento-na-rua-tem-sido-de-estrangeiros-em-lajeado-afirma-proprietario-de-bar/. Acesso em: 29 jul. 2020. 
MARCUS, G. Au-delà de Malinowski et après Writing Culture: à propos du futur de l'anthropologie culturelle et du malaise de l'ethnographie. Ethnographiques.org, n. 1, avril 2002. Disponível em: http://www.ethnographiques.org/2002/Marcus.html. Acesso em: 22 jun. 2012.

MBEMBE, A. Necropolítica. Santa Cruz de Tenerife: Melusina, 2016.

MENDONÇA, H. Covid-19 em frango brasileiro enviado à China, entre a guerra comercial e o medo do contágio. El País, [s. l.], 13 ago. 2020. Disponível em: https:// brasil.elpais.com/brasil/2020-08-14/covid-19-em-frango-brasileiro-enviado-a-china-entre-a-guerra-comercial-e-o-medo-do-contagio.html. Acesso em: 22 ago. 2020.

MILLS, C. W. A imaginação sociológica. Rio de Janeiro: Zahar, 1972.

MOTA, C. V. Covid-19 se alastra em frigoríficos e põe brasileiros e imigrantes em risco. BBC News Brasil, São Paulo, 22 jul. 2020. Disponível em https://www.bbc.com/portuguese/brasil-53477319. Acesso em: 16 ago. 2020.

OLIVEIRA, W. A. de et al. Impactos psicológicos e ocupacionais das sucessivas ondas recentes de pandemias em profissionais da saúde: revisão integrativa e lições aprendidas. Estudos de Psicologia (Campinas), Campinas, v. 37, e200066, 2020. Disponível em: http://www.scielo.br/scielo.php?script=sci_arttext\&pid=S0103-166X20200001 00503\&lng=en\&nrm=iso. Acesso em: 26 maio 2020.

PEDERSINI, H. Encantado tem a primeira morte por Coronavírus. Grupo Encantado de Comunicação, Encantado, 16 maio 2020. Disponível em: https://www.rdencantado. com.br/ultimas-noticias/saude/item/encantado-tem-primeira-morte-por-coronavirus.html. Acesso em: 29 jul. 2020.

RIBEIRO, N. Estrela e Lajeado confirmam os primeiros pacientes infectados como coronavírus no Vale. Grupo Independente, Lajeado, 21 mar. 2020. Disponível em: https://independente.com.br/brf-de-lajeado-tem-quatro-funcionarios-com-covid-19/. Acesso em: 19 ago. 2020.

RIBEIRO, V. S. A interação haitiana em Concórdia/SC. 2018. Monografia (Graduação em Ciências Sociais) - Universidade Federal da Fronteira Sul, Chapecó, 2018. Disponível em: https://rd.uffs.edu.br/handle/prefix/2666. Acesso em: 21 ago. 2020.

RISSON, A.; MAGRO, M.; LAJÚS, M. Imigração e trabalho precário: reflexões acerca da chegada da população haitiana no oeste de Santa Catarina. Périplos: Revista de Estudos Sobre Migrações, Brasília, v. 1, n. 1, p. 144-152, 2017. 
SALES, E. S. Haitianos em Concórdia: relatos de vida em mobilidade. 2016. Trabalho de Conclusão de Curso (Especialização em Gênero e Diversidade na Escola) - Instituto de Estudos de Gênero do Centro de Filosofia e Ciências Humanas, Universidade Federal de Santa Catarina, Florianópolis, 2016. Disponível em: https:// repositorio.ufsc.br/xmlui/bitstream/handle/123456789/173845/TCC\%20Eliete\%20 Sales.pdf?sequence=2\&isAllowed=y. Acesso em: 21 ago. 2020 .

SANTA CATARINA. Decreto n ${ }^{\circ}$ 509, de 17 de março de 2020. Dá continuidade à adoção progressiva de medidas de prevenção e combate ao contágio pelo coronavírus (covid-19) nos órgãos e nas entidades da administração pública estadual direta e indireta e estabelece outras providências. Diário Oficial [do] Estado de Santa Catarina, ano 86, n. 21-223-A, p. 1-2, Florianópolis, 17 mar. 2020.

SC TEM maior taxa de ocupação de leitos de UTI de Covid-19 desde início da pandemia no estado. G1 SC, Florianópolis, 15 maio 2020. Disponível em: https://g1.globo. com/sc/santa-catarina/noticia/2020/05/15/sc-tem-maior-taxa-de-ocupacao-de-leitos-de-uti-de-covid-19-desde-inicio-da-pandemia-no-estado.ghtml. Acesso em: 21 ago. 2020.

SECRETARIA DA SAÚDE (RIO GRANDE DO SUL). Confirmado o primeiro caso de novo coronavírus no Rio Grande do Sul. Porto Alegre: SES, 10 mar. 2020. Disponível em: https://saude.rs.gov.br/confirmado-o-primeiro-caso-de-novo-coronavirus-no-rio-grande-do-sul. Acesso em: 14 jul. 2020.

Recebido: 26/08/2020 Aceito: 20/01/2021 | Received: 8/26/2020 Accepted: 1/20/2021 